\title{
Two faces of the estrogen metabolite 2-methoxyestradiol in vitro and in vivo
}

\author{
JI-SUN LEE, YU-KYUNG KIM, HYUN YANG, HEE YOUNG KANG, \\ CHANGHWAN AHN and EUI-BAE JEUNG
}

Laboratory of Veterinary Biochemistry and Molecular Biology, College of Veterinary Medicine, Chungbuk National University, Cheongju, Chungbuk 362-763, Republic of Korea

Received September 10, 2014; Accepted May 21, 2015

DOI: $10.3892 / \mathrm{mmr} .2015 .4073$

\begin{abstract}
Methoxyestradiol (2-ME), an endogenous metabolite of $17 \beta$-estradiol (E2), interacts with estrogen receptors (ERs) and microtubules, however, 2-ME has a low affinity for ERs. Furthermore, 2-ME has been identified as a potential novel antitumor agent, combining its anti-proliferative effects on a variety of tumor cell types with its anti-angiogenic action. Therefore, 2-ME is of interest due to its potential anticancer therapeutic effects. In the current study, the estrogenic effect of 2-ME on CaBP-9k, ER $\alpha$, and progesterone receptor (PR) mRNA levels in the absence and presence of E2 and progesterone (P4) in in vivo and in vitro models was examined. In $\mathrm{GH} 3$ cells, the mRNA level of CaBP-9k was induced in the E2 treatment group (concentration, $10^{-9} \mathrm{M}$ ), and the expression of CaBP-9k was also upregulated in the 2-ME-treated group (concentration, $10^{-7} \mathrm{M}$ ). Uterine lactoferrin (Ltf) mRNA expression was also increased in the 2-ME group [dose, $40 \mathrm{mg} / \mathrm{kg}$ body weight (BW)], which was comparable to the response with $\mathrm{E} 2$ (dose, $40 \mu \mathrm{g} / \mathrm{kg} \mathrm{BW}$ ) observed in mice. As inhibitors of ER and PR activity, ICI 182,780 and mifepristone (RU486) were observed to reverse the E2 or 2-ME mediated increase of CaBP-9k and Ltf mRNA expression. In addition, it was found that 2-ME significantly decreased the levels of $\mathrm{ER} \alpha$ and increased PR transcripts. Consistent with the in vitro results, the mRNA levels revealed decreased $\mathrm{ER} \alpha$ and increased PR in in vivo treatment of E2 and 2-ME. These findings demonstrate that the expression of estrogenic markers, CaBP-9k and Ltf, is regulated by $2-\mathrm{ME}$ in in vitro and in vivo models, therefore, estrogenic activities of 2-ME may be increased in females during the estrous cycle via the ER and/or PR-mediated signaling pathway.
\end{abstract}

Correspondence to: Professor Eui-Bae Jeung, Laboratory of Veterinary Biochemistry and Molecular Biology, College of Veterinary Medicine, Chungbuk National University, 52 Naesudongro, Cheongju, Chungbuk 362-763, Republic of Korea

E-mail: ebjeung@chungbuk.ac.kr

Key words: 2-methoxyestradiol, 17 $\beta$-estradiol, GH3 cell, CaBP-9k, lactoferrin

\section{Introduction}

2-Methoxyestradiol (2-ME) is a metabolite of the endogenous estrogen hormone, 17ß-estradiol (E2) and the oral contraceptive agent 17 -ethylestradiol, which is produced by sequential hepatic hydroxylation and methylation from the parent compounds (1). 2-ME is generated by catechol-O-methyltransferase, an enzyme expressed in various mammalian tissues, including the liver, kidneys, brain and red blood cells (2). 2-ME is the major catechol estrogen produced by the cytochrome P450 system in the liver (3). Estrogens act as important regulators of cell proliferation, cell survival, and differentiation in a variety of organs and tissues. In addition, estrogens have been implicated in the etiology of a variety of malignant cancers and benign tumors (4).

The estrogen metabolite, 2-ME, is an anti-proliferative and anti-angiogenic molecule that effectively induces apoptosis in actively proliferating cells in vitro and in vivo (5,6). 2-ME was found to act as a potent inhibitor of estrogen-induced proliferation in F344 rat pituitaries (7). Various mechanisms of 2-ME activity have been proposed, such as exerting effects on tubulin polymerization and depolymerization $(8,9)$ or inducing mitochondrial apoptotic signaling (10). In breast cancer, however, higher baseline levels of estrogen and certain estrogen metabolites (total estradiol, bioavailable estradiol, estrone and estrone sulfate) were associated with higher breast cancer risk in post-menopausal females, other forms of the estrogen metabolite, 2-ME were also known as antitumor reagents (11). Estrogens may cause de novo breast cancer through either receptor-dependent or independent mechanisms, and through actions mediated by its receptor, estradiol, which enhances cell proliferation, a factor causally associated with breast cancer development (12). Furthermore, 2-ME is recognized for its unique and profound actions on various tumor cell lines and cancer cells, independent of the hormone receptor status (13). Regardless of differences in function, 2-ME has an affinity for estrogen receptors (ERs) $(14,15)$, however, the underlying mechanisms of 2-ME via ERs have not been fully elucidated.

Previous studies have shown that CaBP-9k, a cytosolic calcium binding protein, is expressed in a variety of mammalian tissues, including the uterus, placenta, the intestine, kidneys, and pituitary glands $(16,17)$. In addition, the CaBP-9k gene is well understood in the uterus and the levels of 
CaBP-9k mRNA and protein, which are induced by endocrine disruptors (EDs), were considered to be facilitative during the screening of environmental estrogenic compounds in an immature rat model (18). In addition, CaBP-9k expression was strongly regulated by sex-steroid hormones in the uterus and pituitary glands of mice $(16,19)$. Uterine lactoferrin (Ltf), an iron-binding glycoprotein that is present in the majority of exocrine secretions and in the secondary granules of leukocytes, is regulated by estrogen in the reproductive tract (20). In previous studies, Ltf was localized in uterine epithelial cells and was shown to fluctuate in a mature mouse, during the estrous cycle, in response to the rise and fall of estrogen levels $(20,21)$. The GH3 cell line, a well-established pituitary cell line, is sensitive to estrogenic stimulation (22). GH3 cells possess an ER that correlates with cell proliferation (23). Yang et al reported that treatment with sex-steroids and EDs induces CaBP-9k expression in GH3 cells (24).

The estrogenic or non-estrogenic activity of estrogen metabolites and EDs has been evaluated in recent studies $(25,26)$. However, the residual effect of high dose 2-ME administered to cancer patients on physiological conditions remains to be fully elucidated. In the current study, it was hypothesized that the estrogenicity of 2-ME may increase the expression of estrogen-mediated genes and contribute to the induction of endocrine disturbance. Therefore, estrogen response genes were investigated using $\mathrm{CaBP}-9 \mathrm{k}$, Ltf, and mRNA expression levels of steroid hormone receptors in in vitro and in vivo models.

\section{Materials and methods}

Chemicals. E2, progesterone (P4) and mifepristone (RU486) were obtained from Sigma-Aldrich (St. Louis, MO, USA). 2-ME and ICI 182,780 were purchased from Tocris Bioscience (Bristol, UK).

Cell culture. GH3 cells were obtained from The Korean Cell Line Bank (Seoul, Republic of Korea). The cells were grown as a monolayer culture in Dulbecco's modified Eagle's medium (DMEM; Gibco Life Technologies, Carlsbad, CA, USA), supplemented with $10 \%$ fetal bovine serum (FBS; Gibco Life Technologies), $100 \mathrm{IU} / \mathrm{ml}$ penicillin and $100 \mu \mathrm{g} / \mathrm{ml}$ streptomycin (Gibco Life Technologies) at $37^{\circ} \mathrm{C}$ in a humidified atmosphere of $5 \% \mathrm{CO}_{2}$. The $\mathrm{GH} 3$ cells were plated on 6-well plastic tissue culture dishes (NUNC, Roskilde, Denmark) at a density of $3 \times 10^{5}$ cells/well and grown until $70-80 \%$ confluence was reached. The media was replaced with phenol red-free DMEM supplemented with 5\% charcoal/dextran (CD)-stripped FBS and $100 \mathrm{U} / \mathrm{ml}$ penicillin-streptomycin for seven days to ensure depletion of the steroid hormones in the cells. The cells used in the present study were grown normally throughout the investigation. After seven days, the cells were exposed to a single dose of E2 $\left(10^{-9} \mathrm{M}\right), \mathrm{P} 4\left(10^{-6} \mathrm{M}\right), 2-\mathrm{ME}$ $\left(10^{-8}, 10^{-7}\right.$ or $\left.10^{-6} \mathrm{M}\right)$. Each chemical was dissolved in $100 \%$ dimethyl sulfoxide (DMSO) and added to phenol red-free DMEM-5\% CD-FBS (starvation media) with a final DMSO concentration of $0.1 \%$. The starvation media with $10^{-9} \mathrm{M}$ E2 served as a positive control and starvation media alone served as the negative control [vehicle (VE)]. The GH3 cells were harvested $24 \mathrm{~h}$ after treatment for measurement of the mRNA levels. To examine the mechanism of CaBP-9k induction by these chemicals, the cells were pre-treated with $10^{-7} \mathrm{M}$ ICI 182,780 and $10^{-6} \mathrm{M}$ RU486 for $30 \mathrm{~min}$ prior to exposure to E2 and 2-ME $(27,28)$. Following treatment with ICI 182,780 and RU486, the cells were treated with E2 $\left(10^{-9} \mathrm{M}\right)$ and 2-ME (at $10^{-8}, 10^{-7}$ or $10^{-6} \mathrm{M}$ ). After $24 \mathrm{~h}$, whole cells were harvested for mRNA analysis. All of the experiments were performed in duplicate.

Animals and treatments. Female Institute for Cancer Research mice (postnatal day 14) were obtained from Koatech Co., Ltd. (Gyeonggi, Republic of Korea) and maintained in the animal facility at the College of Veterinary Medicine, Chungbuk National University (Chungbuk, Republic of Korea). The use of the animals and the experimental procedures were approved by the Institutional Animal Care and Use Committee of Chungbuk National University. All of the animals were housed in polycarbonate cages and used after acclimation to an environmentally controlled room (temperature, $23 \pm 2{ }^{\circ} \mathrm{C}$; relative humidity, $50 \pm 10 \%$; frequent ventilation and a 12:12 h light-dark cycle). The mice were fed soy-free pellet food (Dyets Inc., Bethlehem, PA, USA) and had access to water ad libitum throughout the study. The 35 mice were divided into seven groups ( $n=5$ per group), and each group was administered subcutaneously with 24\% DMSO, 38\% ethanol and $38 \%$ sterile saline (VE), $40 \mu \mathrm{g} / \mathrm{kg}$ body weight (BW) E2 (a physiological dose level), or 4,40 or $80 \mathrm{mg} / \mathrm{kg}$ BW 2-ME for three days. The mice were euthanized $24 \mathrm{~h}$ after the final injection. To investigate the effect of antagonism, 10 rats were injected subcutaneously with $10 \mathrm{mg} / \mathrm{kg}$ BW ICI 182,780 and $10 \mathrm{mg} / \mathrm{kg}$ BW RU486 $30 \mathrm{~min}$ prior to injection with $40 \mathrm{mg} / \mathrm{kg}$ BW 2-ME for three days. The rats were euthanized $24 \mathrm{~h}$ after the final injection.

Uterine wet weight. Mice were sacrificed by cervical dislocation. The uterus was excised completely and trimmed free of fat. The body of the uterus was cut just above the junction with the cervix. The wet weight of the mouse uterus was recorded.

Reverse transcription quantitative polymerase chain reaction (RT-qPCR). Total RNA was extracted using TRI reagent (Ambion Life Technologies, Carlsbad, CA, USA) according to the manufacturer's instructions and the concentration of total RNA was determined by measuring the absorbance at $260 \mathrm{~nm}$. Total RNA $(1 \mu \mathrm{g})$ was reverse transcribed into first-strand cDNA using M-MLV Reverse Transcriptase (Invitrogen Life Technologies, Carlsbad, CA, USA) and 9-mer random primers (Takara Bio, Inc., Otsu, Japan).

RT-qPCR was performed using a 7300 Real-Time PCR system (Applied Biosystems Life Technologies, Foster City, CA, USA) with $1 \mu \mathrm{l}$ cDNA template added to $10 \mu 12 \mathrm{X} \mathrm{SYBR}$ Premix Ex Taq (Takara Bio, Inc.) containing specific primers at a concentration of $10 \mathrm{pM}$ each. The reactions were performed for 40 cycles and the cycling parameters were as follows: Denaturation at $95^{\circ} \mathrm{C}$ for $30 \mathrm{sec}$, annealing at $58^{\circ} \mathrm{C}$ for $30 \mathrm{sec}$ and extension at $72^{\circ} \mathrm{C}$ for $30 \mathrm{sec}$. The fluorescence intensity was measured on termination of the extension phase of each cycle and the threshold value for the fluorescence intensity of all samples was set manually. The reaction cycle at which the PCR products exceeded this fluorescence intensity threshold 
A

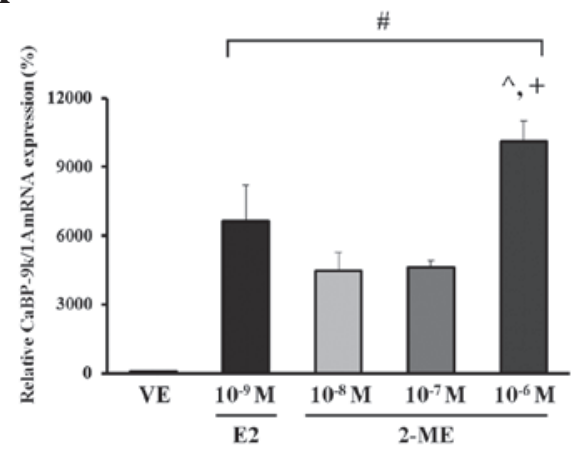

B

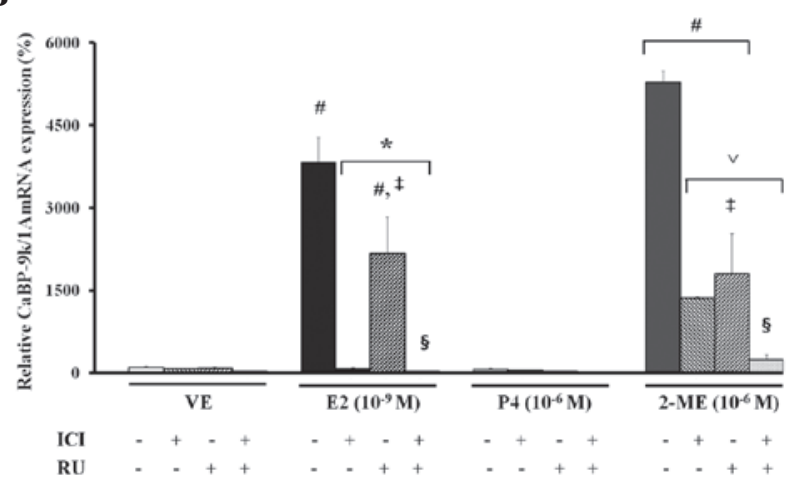

Figure 1. mRNA expression of CaBP-9k under E2, P4 and 2-ME treatment or co-treatment with/without ICI 182,780 or RU486 in GH3 cells. (A) The concentration-dependent effect of 2-ME and E2 on CaBP-9k mRNA expression. (B) Inhibition effects of E2, P4 and 2-ME on CaBP-9k mRNA expression. ${ }^{\# P}<0.05$ compared with VE; ${ }^{*} \mathrm{P}<0.05$ compared with E2 $\left(10^{-9} \mathrm{M}\right) ;{ }^{\wedge} \mathrm{P}<0.05$ compared with $2-\mathrm{ME}\left(10^{-8} \mathrm{M}\right){ }^{+} \mathrm{P}<0.05$ compared with $2-\mathrm{ME}\left(10^{-7} \mathrm{M}\right) ;{ }^{\vee} \mathrm{P}<0.05$ compared with 2-ME $\left(10^{-6} \mathrm{M}\right)$; ${ }^{\ddagger} \mathrm{P}<0.05$ compared with steroids with ICI $\left(10^{-7} \mathrm{M}\right) ;{ }^{\circledR} \mathrm{P}<0.05$ compared with steroids with RU (10 $\left.{ }^{-6} \mathrm{M}\right)$. Each gene was normalized with cytochrome $c$ oxidase subunit 1 gene $(1 \mathrm{~A})$ and served as the internal control for the mRNA concentration. Data are presented as the mean \pm standard error of the mean of triplicate samples. VE, vehicle; E2, 17 $\beta$-estradiol; 2-ME, 2-methoxyestradiol.

in the exponential phase of PCR amplification was taken as the threshold cycle (CT). The PCR product of cytochrome $c$ oxidase subunit 1 (1A, a ubiquitously expressed housekeeping gene) (16) served as a control for mRNA concentrations in the RT-qPCR reactions. The relative expression level of each gene was quantified using RQ study software (Applied Biosystems Life Technologies). The quantity of transcript present was inversely associated with the observed CT and, for every two-fold dilution in the quantity of transcript, CT was expected to increase by one. Relative expression $(R)$ was calculated using the equation $R=2^{-(\Delta \text { CTsample }-\Delta \text { CTcontrol })}$. To determine a normalized arbitrary value for each gene, every data point was normalized to the control gene (1A), as well as to the respective controls. The primers were as follows: Sense, 5'-CCAGGGTTTGGAATTATTTC-3' and antisense, 5'-GAA GATAAACCCTAAGGCTC-3' for rat and mouse 1A; sense, 5'-AAGAGCATTTTTCAAAAATA-3' and antisense, 5'-GTC TCAGAATTTGCTTTATT-3' for rat CaBP-9k; sense, 5'-GAC TTGAATCTCCACGATCA-3' and antisense, 5'-CTTCAA GGTGCTGGATAGAA-3' for rat ER $\alpha$; sense, 5'-TGTGTC CAGCTACAAACCAATG-3' and antisense, 5'-CATCATGCC CACTTCGTAACA-3' for mouse ER $\alpha$; sense, 5'-GAAGAG CAAACCTCGAGCAC-3' and antisense, 5'-AGCAGAAAA CCGGGAATCTT-3' for rat PR; sense, 5'-AATCCCACAGGA GTTTGTCA-3' and antisense, 5'-GGACAACCCCTTTCT GTCTT-3' for mouse PR; and sense, 5'-CTTTAAGGTGTC TGGCTGAGAAG-3' and antisense, 5'-AGTTCTTAGCCT CAGTCACAGGTT-3' for mouse Ltf.

Statistical analysis. The results are presented as the mean \pm standard error of the mean. P-values were calculated using one-way analysis of variance, followed by Tukey's test for multiple comparisons of columns. $\mathrm{P}<0.05$ was considered to indicate a statistically significant difference.

\section{Results}

Effects of 2-ME on regulation of CaBP-9k $m R N A$ expression in GH3 cells. 2-ME was applied to GH3 cells at three concentrations $\left(10^{-8}, 10^{-7}\right.$ and $\left.10^{-6} \mathrm{M}\right)$. CaBP-9k mRNA levels were then analyzed as an estrogen marker of rat pituitary $\mathrm{GH} 3$ cells using RT-qPCR (25). As shown in Fig. 1A, a significant increase in expression of CaBP-9k mRNA was observed at concentrations of $10^{-8}, 10^{-7}$ and $10^{-6} \mathrm{M} 2-\mathrm{ME}$, and $10^{-9} \mathrm{M}$ E2 $(\mathrm{P}<0.02)$. Compared with the VE (negative) controls, the CaBP-9k mRNA level increased by $\sim 66$-fold in the E2-treated $\left(10^{-9} \mathrm{M}\right)$ positive control group and by 44.4 - to 100 -fold in the 2-ME-treated group. The expression of CaBP-9k demonstrated a dose-dependent response to 2-ME; treatment with 2-ME at a dose of $10^{-6} \mathrm{M}$ resulted in a 2.2-fold increase, compared with the $10^{-8}$ or $10^{-7} \mathrm{M}$ treatment group (Fig. 1A). For identification of the steroid hormone receptor signaling pathway involved in transcriptional upregulation of $\mathrm{CaBP}-9 \mathrm{k}$ expression by 2-ME, the GH3 cells were pretreated with the ER antagonist, ICI 182,780 or with the PR antagonist, RU486 (28), which determined that co-treatment with $2-\mathrm{ME}\left(10^{-6} \mathrm{M}\right)$ induced the highest expression of CaBP-9k mRNA among the $10^{-8}, 10^{-7}$ and $10^{-6} \mathrm{M}$ 2-ME doses, and compared with the E2 $\left(10^{-9} \mathrm{M}\right)-$, P4 (10 $\left.{ }^{-6} \mathrm{M}\right)$ - or VE (0.1\% DMSO)-treated groups (Fig. 1B).

CaBP-9k mRNA levels were analyzed using RT-qPCR. As shown in Fig. 1B, induction of CaBP-9k mRNA expression by $\mathrm{E} 2$ and 2-ME was completely abolished by co-treatment with ICI 182,780 at a concentration of $10^{-7} \mathrm{M}$. Results of co-treatment of the PR antagonist, RU486 $\left(10^{-6} \mathrm{M}\right)$ with E2 $\left(10^{-9} \mathrm{M}\right)$ and $2-\mathrm{ME}\left(10^{-6} \mathrm{M}\right)$ induced a significant increase in expression of CaBP-9k mRNA when compared with the VE control $(\mathrm{P}<0.0001)$. Notably, CaBP-9k mRNA expression in the E2- or 2-ME-treated groups following co-treatment with ICI $182,780\left(10^{-7} \mathrm{M}\right)$ and RU486 $\left(10^{-6} \mathrm{M}\right)$ was significantly decreased when compared with co-treatment with RU486 $\left(10^{-6} \mathrm{M}\right)$ alone $(\mathrm{P}<0.0002$; Fig. $1 \mathrm{~B})$.

Effect of 2-ME on mRNA expression of steroid hormone receptors in GH3 cells. 2-ME was applied to GH3 cells at three concentrations $\left(10^{-8}, 10^{-7}\right.$ or $\left.10^{-6} \mathrm{M}\right)$ for evaluation of the potential impact of 2-ME. In addition, the mRNA levels of ER $\alpha$ between ER $\alpha$ and PR were measured to evaluate the estrogenicity of estrogen metabolite, 2-ME (27). GH3 cells were treated with $2-\mathrm{ME}\left(10^{-8}, 10^{-7}\right.$ and $\left.10^{-6} \mathrm{M}\right)$, E2 $\left(10^{-9} \mathrm{M}\right)$ or the VE (0.1\% DMSO). Compared with the VE control, E2 
A

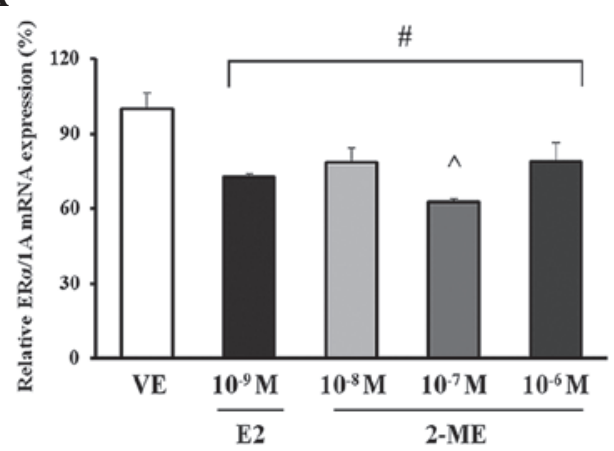

C

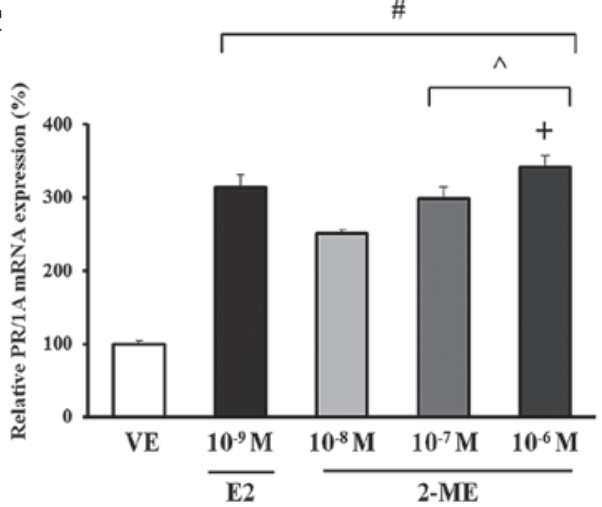

B

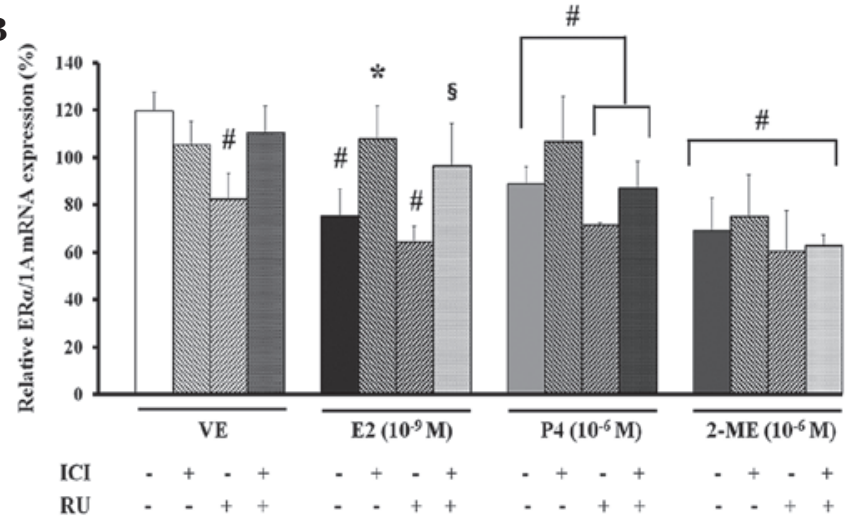

$\mathbf{D}$

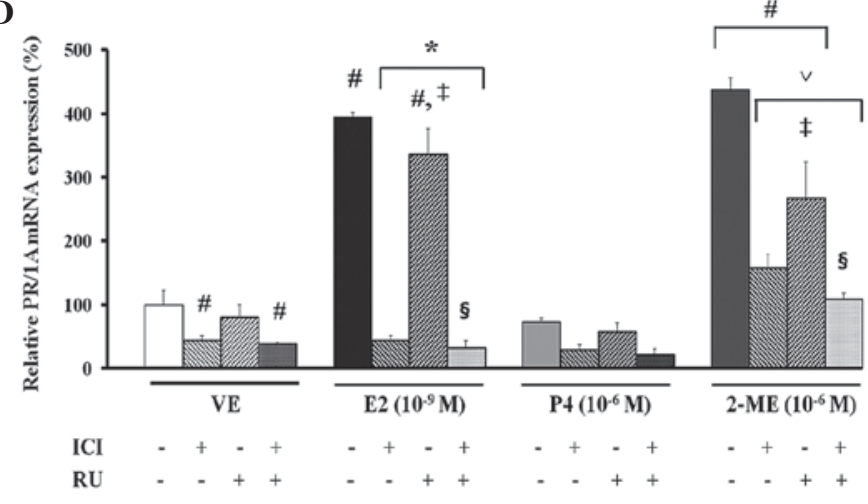

Figure 2. mRNA expression of ER $\alpha$ and PR under E2, P4 and 2-ME treatment or co-treatment with/without ICI 182,780 or RU486 in GH3 cells. (A) The concentration-dependent effect of 2-ME and E2 on ER $\alpha$ mRNA expression. (B) Inhibition effects of E2, P4 and 2-ME on ER $\alpha$ mRNA expression. (C) The concentration-dependent effect of $2-\mathrm{ME}$ and E2 on PR mRNA expression. (D) Inhibition effects of E2, P4 and 2-ME on PR mRNA expression. ${ }^{\#} \mathrm{P}<0.05$ compared with VE; * $\mathrm{P}<0.05$ compared with $\mathrm{E} 2\left(10^{-9} \mathrm{M}\right) ;{ }^{\wedge} \mathrm{P}<0.05$ compared with $2-\mathrm{ME}\left(10^{-8} \mathrm{M}\right){ }^{+} \mathrm{P}<0.05$ compared with $2-\mathrm{ME}\left(10^{-7} \mathrm{M}\right)$; ${ }^{\vee} \mathrm{P}<0.05$ compared with 2-ME $\left(10^{-6} \mathrm{M}\right) ;{ }^{\dagger} \mathrm{P}<0.05$ compared with steroids with ICI $\left(10^{-7} \mathrm{M}\right) ;{ }^{\circledR} \mathrm{P}<0.05$ compared with steroids with RU (10 $\left.{ }^{-6} \mathrm{M}\right)$. Each gene was normalized with cytochrome $c$ oxidase subunit 1 gene $(1 \mathrm{~A})$ and served as the internal control for the mRNA concentration. Data are presented as the mean \pm standard error of the mean of triplicate samples. VE, vehicle; E2, 17 $\beta$-estradiol; 2-ME, 2-methoxyestradiol; ER $\alpha$, estrogen receptor $\alpha$; PR, progesterone receptor.

induced a decrease of $\sim 1.4$-fold and treatment with all doses of 2-ME resulted in decreased expression of ER $\alpha$ mRNA by $\sim 1.2$ - to 1.3-fold (Fig. 2A). The dose-dependent response of 2-ME on ER $\alpha$ gene expression was observed in the $10^{-7} \mathrm{M}$ treatment group compared with the $10^{-8} \mathrm{M} 2-\mathrm{ME}$ treatment group. In addition, the 2-ME treatment group experienced a similar response to that of the E2 treatment group by demonstrating a decrease in ER expression levels (Fig. 2A).

For identification of the steroid hormone receptor signaling pathway involved in transcriptional upregulation of CaBP-9k mRNA expression by $2-\mathrm{ME}$, the GH3 cells were pretreated with the ER antagonist, ICI 182,780 or with the PR antagonist, RU486 (28). In the case of ER $\alpha$ mRNA expression compared with the VE control, E2 induced a decrease of $\sim 1.5$-fold and treatment with ICI 182,780 and/or RU486 induced 2-ME resulted in a decrease of $\sim 1.7$ - to 1.9-fold (Fig. 2B). Notably, $\mathrm{ER} \alpha \mathrm{mRNA}$ expression in the E2 treatment group, as a result of co-treatment with ICI 182,780 $\left(10^{-7} \mathrm{M}\right)$ and RU486 $\left(10^{-6} \mathrm{M}\right)$, was markedly increased compared with co-treatment with RU486 $\left(10^{-6} \mathrm{M}\right)$ alone (Fig. $\left.2 \mathrm{~B} ; \mathrm{P}<0.005\right)$. In the case of PR mRNA expression, the positive control, E2, and all doses of 2-ME induced a significant increase in expression of PR mRNA compared with the VE (Fig. 2C; P<0.0003).

For identification of the steroid hormone receptor signaling pathway involved in transcriptional regulation of PR mRNA expression by 2-ME, GH3 cells were pretreated with the ER antagonist, ICI 182,780 or with the PR antagonist, RU486 (28). Compared with VE, the E2 and 2-ME treatment groups showed a significantly increased pattern of PR expression $(\mathrm{P}<0.0001)$. Of particular interest, $\mathrm{PR}$ mRNA expression resulting from co-treatment with ICI $182,780\left(10^{-7} \mathrm{M}\right)$ and RU486 $\left(10^{-6} \mathrm{M}\right)$ in the E2 or 2-ME treatment groups was markedly decreased compared with co-treatment with RU486 $\left(10^{-6} \mathrm{M}\right)$ alone (Fig. 2D; $\left.\mathrm{P}<0.0001\right)$. Thus, the magnitude and pattern of induction of PR mRNA by 2-ME were very similar to the enhanced expression of CaBP-9k following treatment with 2-ME (Fig. 1A and 2C; Fig. 1B and 2D).

Effects of 2-ME on uterine wet weight. A uterotrophic assay was used to identify an estrogen-like effect (26). The effects were determined by subcutaneous injection with 2-ME $(4,40$ or $80 \mathrm{mg} / \mathrm{kg} \mathrm{BW})$ or E2 $(40 \mu \mathrm{g} / \mathrm{kg} \mathrm{BW})$. ICI 182,780 or RU486 were treated with $2-\mathrm{ME}(40 \mathrm{mg} / \mathrm{kg} \mathrm{BW})$ for determining the steroid hormone receptor signaling pathway involved in 2-ME. Compared with the VE, an $~ 3.9$-fold increase in uterine wet weight was observed upon treatment with $40 \mu \mathrm{g} / \mathrm{kg}$ BW E2, and 4.1- to 5.0-fold increase at 4, 40 and $80 \mathrm{mg} / \mathrm{kg} \mathrm{BW} 2-\mathrm{ME}$. However, no significant dose-dependent result was observed for any dose of 2-ME (Fig. 3A; P<0.05). Due to demonstrating the greatest increase in uterine wet weight among the 4,40 and $80 \mathrm{mg} / \mathrm{kg} \mathrm{BW}$ doses of 2-ME, the steroid hormone receptor antagonist treatment of $40 \mathrm{mg} / \mathrm{kg} \mathrm{BW} 2-\mathrm{ME}$, became the focus 
A

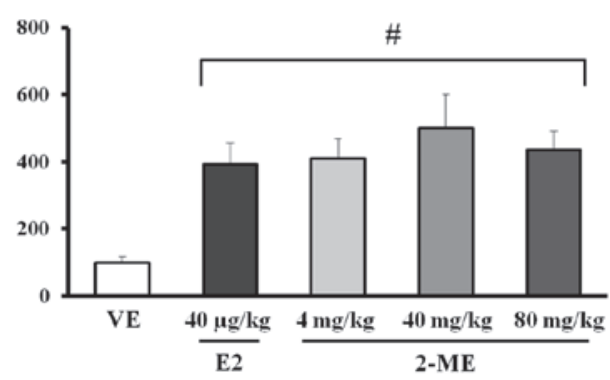

C

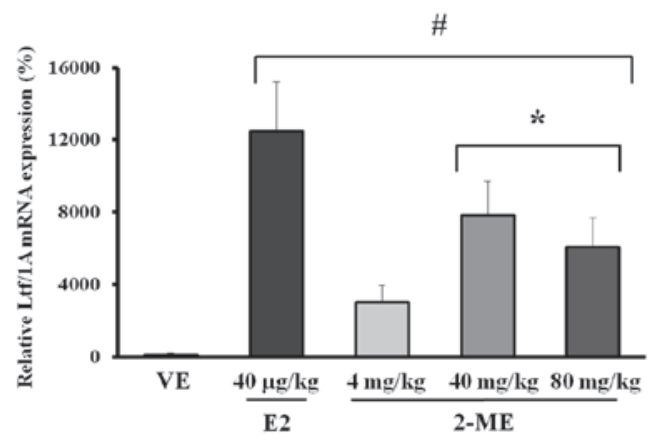

B

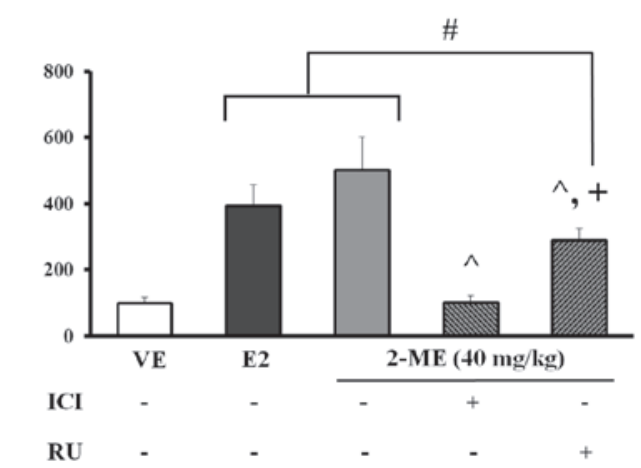

D

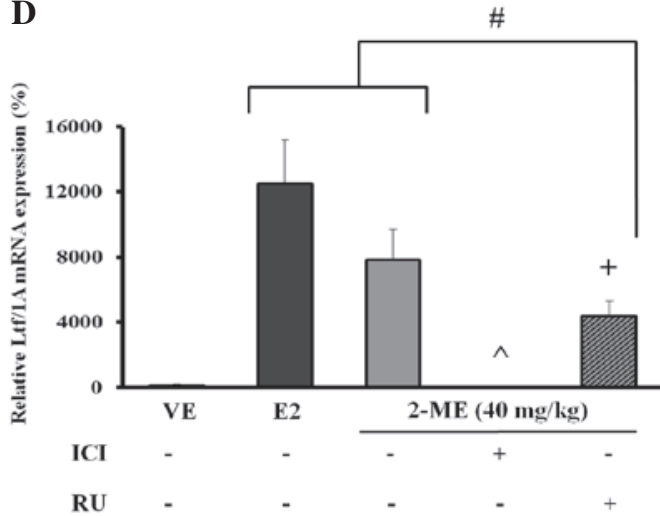

Figure 3. Uterine weight and mRNA expression of Ltf under E2 and 2-ME treatment or co-treatment with/without ICI 182,780 or RU486 on 2-ME induced mice. (A) The concentration-dependent effect of 2-ME and E2 on mice uterus weight. (B) Inhibition effects of 2-ME on mice uterus weight. (C) The concentration-dependent effect of 2-ME and E2 on Ltf mRNA expression. (D) Inhibition effects of 2-ME on Lft mRNA expression. " $\mathrm{P}<0.05$ compared with VE; ${ }^{*} \mathrm{P}<0.05$ compared with 2-ME (4 mg/kg BW); ${ }^{\wedge} \mathrm{P}<0.05$ compared with $2-\mathrm{ME}(40 \mathrm{mg} / \mathrm{kg} \mathrm{BW}) ;{ }^{+} \mathrm{P}<0.05 \mathrm{compared}$ with $2-\mathrm{ME}(40 \mathrm{mg} / \mathrm{kg} \mathrm{BW}) \mathrm{with} \mathrm{ICI}(10 \mathrm{mg} / \mathrm{kg} \mathrm{BW})$. Each gene was normalized with cytochrome $c$ oxidase subunit 1 gene (1A) and served as the internal control for the mRNA concentration. Data is presented as the mean \pm standard error of the mean of duplicate samples. VE, vehicle; E2, 17ß-estradiol; 2-ME, 2-methoxyestradiol; Ltf, uterine lactoferrin.

(Fig. 3A). Co-treatment with ICI 182,780 (10 mg/kg BW) on 2-ME (40 mg/kg BW) induced a 5-fold decrease compared with 2-ME alone $(\mathrm{P}<0.0001)$. In addition, RU486 treatment on 2-ME (40 mg/kg BW) induced a significant 1.7-fold decrease compared with 2-ME alone. Notably, co-treatment with RU486 in the 2-ME treatment group resulted in a 2.8 -fold increase when compared with ICI 182,780 co-treatment (Fig. 3B).

Effects of 2-ME on the regulation of Ltf gene mRNA expression in the uterus of mice. To evaluate the potential impact of 2-ME, Ltf mRNA levels were analyzed as an estrogen marker of rodents using RT-qPCR (29). When compared with the VE control, E2 at $40 \mu \mathrm{g} / \mathrm{kg}$ BW induced an $\sim 125$-fold increase in Ltf mRNA expression and 2-ME at $40 \mathrm{mg} / \mathrm{kg} \mathrm{BW}$ induced an 78 .3-fold increase. Furthermore, treatment with 2-ME at $80 \mathrm{mg} / \mathrm{kg}$ BW resulted in an $~ 60.7$-fold increase in Ltf mRNA expression. In particular, the dose of $40 \mathrm{mg} / \mathrm{kg}$ BW 2-ME demonstrated the most similarity with E2 among the three doses of 2-ME, as shown by the increased Ltf gene expression level (Fig. 3C).

For identification of the steroid hormone receptor signaling pathway involved in transcriptional upregulation of Ltf gene expression by 2-ME, mice were pre-injected with the ER antagonist, ICI 182,780 , at $10 \mathrm{mg} / \mathrm{kg} \mathrm{BW}$ or with the PR antagonist, RU486, at $10 \mathrm{mg} / \mathrm{kg} \mathrm{BW}$ (28). E2 at $40 \mu \mathrm{g} / \mathrm{kg} \mathrm{BW}$ and $2-\mathrm{ME}$ at $40 \mathrm{mg} / \mathrm{kg} \mathrm{BW}$ were analyzed and co-treatment of RU486 (10 mg/kg BW) with 2-ME (40 mg/kg BW) induced significantly increased Ltf gene expression when compared with the VE $(\mathrm{P}<0.004)$. In addition, $2-\mathrm{ME}(40 \mathrm{mg} / \mathrm{kg} \mathrm{BW})$ was completely abolished by treatment with ICI 182,780 (10 mg/kg BW). Notably, co-treatment of RU486 with 2-ME resulted in a significant 470 -fold increase when compared with co-treatment of ICI 182,780 and 2-ME (Fig. 3D; P<0.003).

Effect of 2-ME on mRNA expression of steroid hormone receptors in the uterus of mice. For evaluation of the potential impact of 2-ME, the mRNA levels of ER $\alpha$ and PR, which respond to materials similar to natural and synthetic estrogen were determined (27). Mice received a subcutaneous injection of 2-ME (4, 40 and $80 \mathrm{mg} / \mathrm{kg} \mathrm{BW})$, E2 (40 $\mu \mathrm{g} / \mathrm{kg} \mathrm{BW})$ or VE (24\% DMSO, 38\% ethanol and 38\% sterile saline). Treatment with 2-ME (4, 40 and $80 \mathrm{mg} / \mathrm{kg} \mathrm{BW})$ or E2 (40 $\mu \mathrm{g} / \mathrm{kg} \mathrm{BW})$ resulted in a decreasing pattern of $\mathrm{ER} \alpha$ when compared with the VE, however, the differences were not considered to be significant, apart from 2-ME in the $80 \mathrm{mg} / \mathrm{kg} \mathrm{BW}$ treatment group. In addition, no dose-dependent response on ER $\alpha$ expression was observed at any of the doses of 2-ME (Fig. 4A).

For identification of the steroid hormone receptor signaling pathway involved in transcriptional upregulation of Ltf mRNA expression by $2-\mathrm{ME}$, the mice were pretreated with the ER antagonist, ICI 182,780 or with the PR antagonist, RU486. In the case of ER $\alpha$, co-treatment with ICI $182,780(10 \mathrm{mg} / \mathrm{kg}$ 
A

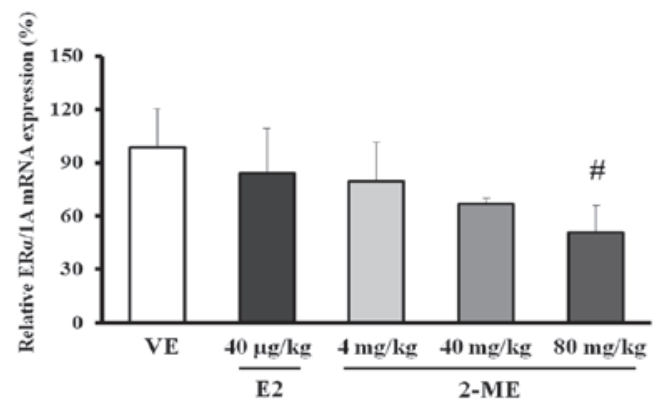

C

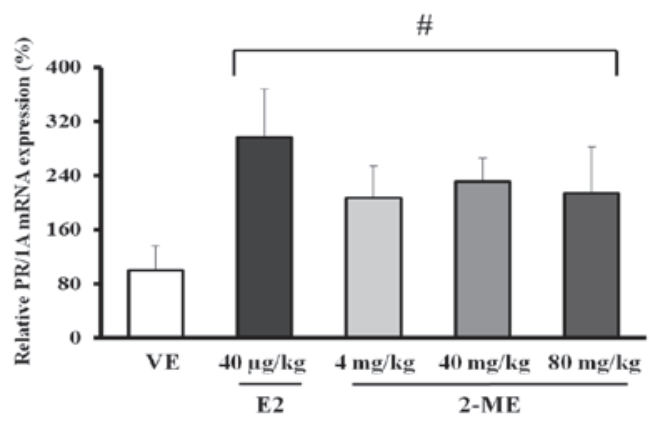

B

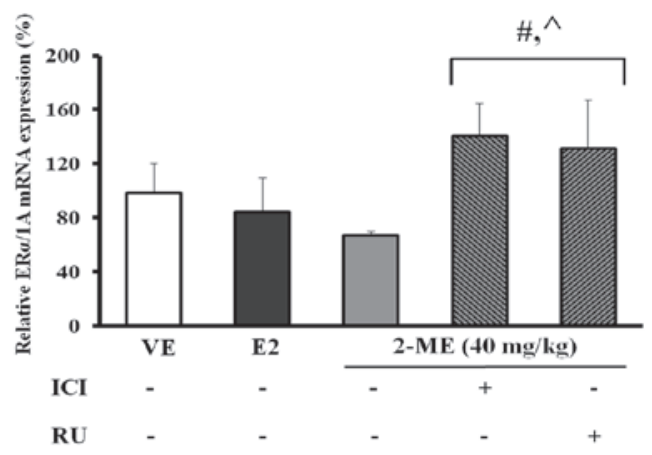

D

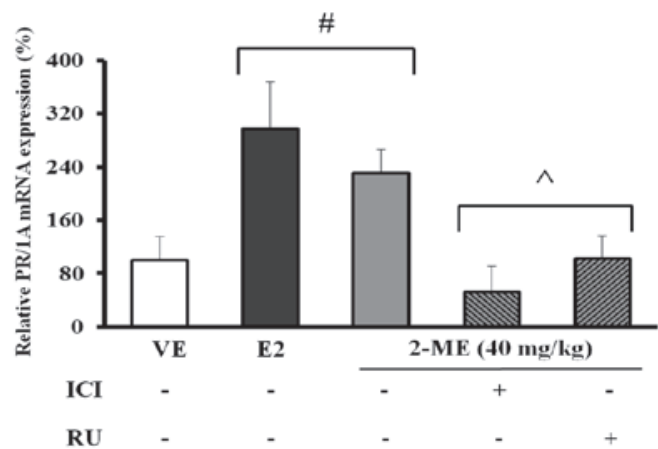

Figure 4. mRNA expression of ER $\alpha$ and PR under E2 and 2-ME treatment or co-treatment with/without ICI 182,780 or RU486 on 2-ME induced mice. (A) The concentration-dependent effect of 2-ME and E2 on ER $\alpha$ mRNA expression. (B) Inhibition effects of 2-ME on ER $\alpha$ mRNA expression. (C) The concentration-dependent effect of 2-ME and E2 on PR mRNA expression. (D) Inhibition effects of 2-ME on PR mRNA expression. ${ }^{\#} \mathrm{P}<0.05$ compared with $\mathrm{VE},{ }^{\wedge} \mathrm{P}<0.05$ compared with $2-\mathrm{ME}(40 \mathrm{mg} / \mathrm{kg} \mathrm{BW})$. Each gene was normalized with cytochrome $c$ oxidase subunit 1 gene (1A) and served as the internal control for the mRNA concentration. Data are presented as the mean \pm standard error of the mean of duplicate samples. VE, vehicle; E2, 17 $\beta$-estradiol; 2 -ME, 2-methoxyestradiol; ER $\alpha$, estrogen receptor $\alpha$; PR, progesterone receptor.

BW) or RU486 (10 mg/kg BW) on 2-ME $\left(10^{-6} \mathrm{M}\right)$ induced a marked increase in ER $\alpha$ mRNA expression of 1.42-fold when compared with 2-ME alone (Fig. 4B; $\mathrm{P}<0.02$ ). In the case of PR mRNA expression, PR showed an increase of 2.94 -fold in the E2 treatment group when compared with the VE and an increase of 2 .1- to 2.3-fold was observed for all doses in the 2-ME (4, 40 and $80 \mathrm{mg} / \mathrm{kg} \mathrm{BW}$ ) treatment group; however, a dose-response effect of 2-ME was not observed (Fig. 4C).

For identification of the steroid hormone receptor signaling pathway involved in transcriptional upregulation of Ltf mRNA expression by 2-ME, mice were pretreated with the ER antagonist, ICI 182,780 or with PR antagonist, RU486. When compared with the VE control, treatment with E2 and 2-ME resulted in a marked increase in PR mRNA expression. Co-treatment with ICI $182,780(10 \mathrm{mg} / \mathrm{kg} \mathrm{BW})$ or RU486 (10 mg/kg BW) on 2-ME resulted in a significant decrease in PR mRNA expression when compared with administration of 2-ME (40 mg/kg BW) alone $(\mathrm{P}<0.002)$. In addition, co-treatment with RU486 on 2-ME resulted in an increase in PR mRNA expression when compared with co-treatment with ICI 182,780; however, the increase was not significant (Fig. 4D).

\section{Discussion}

Previously, the effect of pharmacological levels of 2-ME on normal physiological systems has not been adequately described. Although the various possible mechanisms of 2-ME were not fully elucidated, 2-ME has been administered as an antitumor therapy. For example, in vitro, 2-ME has been shown to affect angiogenesis and proliferation of malignant cells, and in vivo, 2-ME was demonstrated to inhibit the growth of tumors arising from a subcutaneous injection in mice (30). To the best of our knowledge, the estrogenic activity in vitro and in vivo of the estradiol metabolite, 2-ME has not been fully determined. The present study indicates that 2-ME exhibits estrogenicity under in vitro and in vivo conditions.

The CaBP-9k gene is known to be controlled by sex hormones. Expression of the CaBP-9k gene was shown to be upregulated by estrogen and downregulated by $\mathrm{P} 4$ during the estrous cycle and early pregnancy in a rat uterus $(31,32)$. In the current study, CaBP-9k expression in GH3 cells was demonstrated as a useful marker for evaluating the estrogenic potential of environmental chemicals, such as parabens (27). Thus, the present findings, showing induction of CaBP-9k gene mRNA expression in GH3 cells demonstrate that 2-ME may have an estrogenic affect. In addition, 2-ME shares the effects of estradiol, such as increasing uterine weight, and the data obtained in the current study indicated the presence of circulating estrogens, which was indicated by the antagonism of uterine wet weights by ICI 182,780 (33). In mice, the Ltf gene expression caused by exposure to estrogen was shown to be associated with an estrogen-stimulated mouse uterus (29). 
During the present study, it was demonstrated that 2-ME mediates the estrogen biomarker gene. Changes in biomarker expression could be expected to result from this ER-dependent action that would be matched by E2-induced effects. ER $\alpha$ is expressed in the uterus, mammary glands, testes, pituitary gland, liver, kidneys and heart (34). ER $\beta$ is found in the prostate and ovaries (35-37). According to Akbas et al, the ER $\alpha$ mRNA expression of the bilateral ovariectomized uterus of adult mice was decreased by treatment with E2 when compared with untreated mice (38). The present result indicated that the effect of 2-ME on ER $\alpha$ mRNA expression may partly result from reduced binding to and signaling through the ER $\alpha$ pathway, which is blocked by pure antiestrogen. Estrogenic chemicals, such as parabens, induce an increase in PR gene expression, which is known to be highly sensitive to, and enhanced by, ER-mediated transcriptional signaling. Therefore, almost all ER-dependent signaling may contribute significantly to the enhanced expression of CaBP-9k and PR genes by specific paraben compounds in in vitro models (39). In the present study, the effect of 2-ME on Ltf and PR expression may partly result from binding to and signaling through the PR pathway, which is blocked by pure anti-P4.

2-ME is known as a potential novel antitumor agent combining its anti-proliferative activity on a wide range of tumor cell types with anti-angiogenic action (40). Combination treatment with agents that possess anti-proliferative and anti-angiogenic activity results in antitumor synergy and reduces the likelihood of antitumor drug resistance (41). For example, in vitro, 2-ME demonstrated the strongest inhibitory effect of all of the estrogen metabolites tested, with a half-maximal inhibitory concentration of $\sim 0.15 \mu \mathrm{M}(30)$. In addition, it exhibited a highly similar growth-inhibitory effect in human breast cancer cell lines, and this effect was not altered by the presence or absence of exogenous E2 (42). Similarly, in vivo, it was reported that a $100-\mathrm{mg} / \mathrm{kg}$ dose of 2-ME inhibited tumor growth in various models with dramatic suppression of longitudinal bone growth in ovary-intact young, growing rats (43). However, low levels of 2-ME may have an influence on females during pregnancy. Preeclampsia, hypoxia and placental defects lead to deficiency in placenta-derived hydroxyestradiols, which in turn may result in a further decrease in the 2-ME level (44).

2-ME was found to be rapidly removed from the plasma and was below the limit of detection $(11 \mathrm{ng} / \mathrm{ml}) 1 \mathrm{~h}$ after administration of a $10-\mathrm{mg} / \mathrm{kg}$ dose. Following, intravenous administration of $2-\mathrm{ME}$, its half-life in plasma was $\sim 14$ min (45). Despite numerous studies on the effect of pharmacological levels of 2-ME on normal physiological systems, it remains to be described fully.

In conclusion, the results of the present study (based on uterine wet weight gain, and increasing levels of estrogen biomarkers in in vitro and in vivo models) demonstrate that all experimental doses of 2-ME, which were lower than anticancer therapeutic concentrations, exerted an estrogenic effect. In addition, the estrogenic activity of 2-ME was observed to be blocked by the ER and PR antagonists, ICI 182,780 and RU486, respectively, in the in vitro and in vivo models. Since 2-ME shows proliferative effects, it is necessary that potential risk of 2-ME should be further investigated as cancer therapeutic reagents., which may affect endocrine homeostasis and/or function. Overall, the present results reveal that 2-ME may impact the ER and PR, and maintain the body in a state of disturbance of the endocrine system.

\section{Acknowledgements}

The present study was supported by a National Research Foundation of Korea grant from the Korean government, Ministry of Education, Science and Technology (grant no. NRF-2013R1A2A2A05004582).

\section{References}

1. Wang SH, Myc A, Koenig RJ, Bretz JD, Arscott PL and Baker JR: 2-Methoxyestradiol, an endogenous estrogen metabolite, induces thyroid cell apoptosis. Mol Cell Endocrinol 165: $163-172,2000$

2. Männistö PT and Kaakkola S: Catechol-O-methyltransferase (COMT): Biochemistry, molecular biology, pharmacology, and clinical efficacy of the new selective COMT inhibitors. Pharmacol Rev 51: 593-628, 1999.

3. Zhang Y, Gaikwad NW, Olson K, Zahid M, Cavalieri EL and Rogan EG: Cytochrome P450 isoforms catalyze formation of catechol estrogen quinones that react with DNA. Metabolism 56: 887-894, 2007.

4. Spady TJ, McComb RD and Shull JD: Estrogen action in the regulation of cell proliferation, cell survival, and tumorigenesis in the rat anterior pituitary gland. Endocrine 11: 217-233, 1999.

5. Pribluda VS, Gubish ER Jr, Lavallee TM, Treston A, Swartz GM and Green SJ: 2-Methoxyestradiol: An endogenous antiangiogenic and antiproliferative drug candidate. Cancer Metastasis Rev 19: 173-179, 2000.

6. Hamel E, Lin CM, Flynn E and D'Amato RJ: Interactions of 2-methoxyestradiol, an endogenous mammalian metabolite, with unpolymerized tubulin and with tubulin polymers. Biochemistry 35: 1304-1310, 1996.

7. Banerjeei SK, Zoubine MN, Sarkar DK, Weston AP, Shah JH and Campbell DR: 2-Methoxyestradiol blocks estrogen-induced rat pituitary tumor growth and tumor angiogenesis: Possible role of vascular endothelial growth factor. Anticancer Res 20: 2641-2645, 2000.

8. D'Amato RJ, Lin CM, Flynn E, Folkman J and Hamel E: 2-Methoxyestradiol, an endogenous mammalian metabolite, inhibits tubulin polymerization by interacting at the colchicine site. Proc Natl Acad Sci USA 91: 3964-3968, 1994.

9. Attalla H, Westberg JA, Andersson LC, Adlercreutz $\mathrm{H}$ and Mäkelä TP: 2-Methoxyestradiol-induced phosphorylation of Bcl-2: Uncoupling from JNK/SAPK activation. Biochem Biophys Res Commun 247: 616-619, 1998.

10. Chang I, Majid S, Saini S, Zaman MS, Yamamura S, Chiyomaru T, Shahryari V, Fukuhara S, Deng G, Dahiya R, et al: Hrk mediates 2-methoxyestradiol-induced mitochondrial apoptotic signaling in prostate cancer cells. Mol Cancer Ther 12: 1049-1059, 2013.

11. Farhat GN, Parimi N, Chlebowski RT, Manson JE, Anderson G, Huang AJ, Vittinghoff E, Lee JS, Lacroix AZ, Cauley JA, et al: Sex hormone levels and risk of breast cancer with estrogen plus progestin. J Natl Cancer Inst 105: 1496-1503, 2013.

12. Yue W, Yager JD, Wang JP, Jupe ER and Santen RJ: Estrogen receptor-dependent and independent mechanisms of breast cancer carcinogenesis. Steroids 78: 161-170, 2013.

13. Gökmen-Polar Y, Escuin D, Walls CD, Soule SE, Wang Y, Sanders KL, Lavallee TM, Wang M, Guenther BD, Giannakakou $\mathrm{P}$, et al: Beta-Tubulin mutations are associated with resistance to 2-methoxyestradiol in MDA-MB-435 cancer cells. Cancer Res 65: 9406-9414, 2005.

14. Zhu BT and Conney AH: Is 2-methoxyestradiol an endogenous estrogen metabolite that inhibits mammary carcinogenesis? Cancer Res 58: 2269-2277, 1998.

15. Brueggemeier RW and Singh U: Inhibition of rat liver microsomal estrogen 2-hydroxylase by 2-methoxyestrogens. J Steroid Biochem 33: 589-593, 1989.

16. Tinnanooru P, Dang VH, Nguyen TH, Lee GS, Choi KC and Jeung EB: Estrogen regulates the localization and expression of calbindin-D9k in the pituitary gland of immature male rats via the ERalpha-pathway. Mol Cell Endocrinol 285: 26-33, 2008. 
17. Lee GS, Choi KC, Park SM, An BS, Cho MC and Jeung EB: Expression of human Calbindin-D (9k) correlated with age, vitamin $\mathrm{D}$ receptor and blood calcium level in the gastrointestinal tissues. Clin Biochem 36: 255-261, 2003.

18. Dang VH, Nguyen TH, Choi KC and Jeung EB: A calcium-binding protein, calbindin-D9k, is regulated through an estrogen-receptor mediated mechanism following xenoestrogen exposure in the GH3 cell line. Toxicol Sci 98: 408-415, 2007.

19. Hong EJ, Park SH, Choi KC, Leung PC and Jeung EB: Identification of estrogen-regulated genes by microarray analysis of the uterus of immature rats exposed to endocrine disrupting chemicals. Reprod Biol Endocrinol 4: 49, 2006.

20. Walmer DK, Wrona MA, Hughes CL and Nelson KG: Lactoferrin expression in the mouse reproductive tract during the natura estrous cycle: Correlation with circulating estradiol and progesterone. Endocrinology 131: 1458-1466, 1992.

21. Newbold RR, Teng CT, Beckman WC Jr, Jefferson WN, Hanson RB, Miller JV and McLachlan JA: Fluctuations of lactoferrin protein and messenger ribonucleic acid in the reproductive tract of the mouse during the estrous cycle. Biol Reprod 47: 903-915, 1992.

22. Fujimoto N, Jinno N and Kitamura S: Activation of estrogen response element dependent transcription by thyroid hormone with increase in estrogen receptor levels in a rat pituitary cell line, GH3. J Endocrinol 181: 77-83, 2004.

23. Banerjee SN, Sengupta K, Banerjee S, Saxena NK and Banerjee SK 2-Methoxyestradiol exhibits a biphasic effect on VEGF-A in tumor cells and upregulation is mediated through ER-alpha: A possible signaling pathway associated with the impact of 2-ME2 on proliferative cells. Neoplasia 5: 417-426, 2003.

24. Yang H, Nguyen TT, An BS, Choi KC and Jeung EB: Synergistic effects of parabens on the induction of calbindin-D (9k) gene expression act via a progesterone receptor-mediated pathway in GH3 cells. Hum Exp Toxicol 31: 134-144, 2012.

25. Vo TT, An BS, Yang H, Jung EM, Hwang I and Jeung EB Calbindin-D9k as a sensitive molecular biomarker for evaluating the synergistic impact of estrogenic chemicals on $\mathrm{GH} 3$ rat pituitary cells. Int J Mol Med 30: 1233-1240, 2012.

26. Jung EM, An BS, Choi KC and Jeung EB: Potential estrogenic activity of triclosan in the uterus of immature rats and rat pituitary GH3 cells. Toxicol Lett 208: 142-148, 2012.

27. Vo TT, Jung EM, Choi KC, Yu FH and Jeung EB: Estrogen receptor $\alpha$ is involved in the induction of Calbindin-D (9k) and progesterone receptor by parabens in GH3 cells: A biomarker gene for screening xenoestrogens. Steroids 76: 675-681, 2011

28. Ahn HJ, Yang H, An BS, Choi KC and Jeung EB: Expression and regulation of Enpp2 in rat uterus during the estrous cycle. J Vet Sci 12: 379-385, 2011

29. Wang Y, Tu Y, Han F, Xu Z and Wang J: Developmental gene expression of lactoferrin and effect of dietary iron on gene regulation of lactoferrin in mouse mammary gland. J Dairy Sci 88: 2065-2071, 2005.

30. Fotsis T, Zhang Y, Pepper MS, Adlercreutz H, Montesano R, Nawroth PP and Schweigerer L: The endogenous oestrogen metabolite 2-methoxyoestradiol inhibits angiogenesis and suppresses tumour growth. Nature 368: 237-239, 1994.
31. Krisinger J, Setoyama $\mathrm{T}$ and Leung PC: Expression of calbindin-D9k in the early pregnant rat uterus: Effects of RU 486 and correlation to estrogen receptor mRNA. Mol Cell Endocrinol 102: 15-22, 1994

32. Krisinger J, Dann JL, Currie WD, Jeung EB and Leung PC: Calbindin-D9k mRNA is tightly regulated during the estrous cycle in the rat uterus. Mol Cell Endocrinol 86: 119-123, 1992.

33. Sibonga JD, Lotinun S, Evans GL, Pribluda VS, Green SJ and Turner RT: Dose-response effects of 2-methoxyestradiol on estrogen target tissues in the ovariectomized rat. Endocrinology 144: 785-792, 2003.

34. Williams K, McKinnell C, Saunders PT, Walker M, Fisher JS, Turner KJ, Atanassova N and Sharpe M: Neonatal exposure to potent and environmental oestrogens and abnormalities of the male reproductive system in the rat: Evidence for importance of the androgen-oestrogen balance and assessment of the relevance to man. Hum Reprod Update 7: 236-247, 2001.

35. Swedenborg E, Pongratz I and Gustafsson JA: Endocrine disruptors targeting ERbeta function. Int J Androl 33: 288-297, 2010.

36. Keightley MC: Steroid receptor isoforms: Exception or rule? Mol Cell Endocrinol 137: 1-5, 1998.

37. Mangelsdorf DJ, Thummel C, Beato M, Herrlich P, Schütz G, Umesono K, Blumberg B, Kastner P, Mark M, Chambon P, et al: The nuclear receptor superfamily: The second decade. Cell 83: 835-839, 1995

38. Akbas GE, Fei X and Taylor HS: Regulation of HOXA10 expression by phytoestrogens. Am J Physiol Endocrinol Metab 292: E435-E442, 2007.

39. Kim YR, Jung EM, Choi KC and Jeung EB: Synergistic effects of octylphenol and isobutyl paraben on the expression of calbindin-D (9)k in GH3 rat pituitary cells. Int J Mol Med 29: 294-302, 2012

40. Mooberry SL: New insights into 2-methoxyestradiol, a promising antiangiogenic and antitumor agent. Curr Opin Oncol 15: 425-430, 2003.

41. Browder T, Butterfield CE, Kräling BM, Shi B, Marshall B, O'Reilly MS and Folkman J: Antiangiogenic scheduling of chemotherapy improves efficacy against experimental drug-resistant cancer. Cancer Res 60: 1878-1886, 2000.

42. Liu ZJ and Zhu BT: Concentration-dependent mitogenic and antiproliferative actions of 2-methoxyestradiol in estrogen receptor-positive human breast cancer cells. J Steroid Biochem Mol Biol 88: 265-275, 2004

43. Turner RT and Evans GL: 2-Methoxyestradiol inhibits longitudinal bone growth in normal female rats. Calcif Tissue Int 66: 465-469, 2000 .

44. Takanashi K, Honma T, Kashiwagi T, Honjo $\mathrm{H}$ and Yoshizawa I: Detection and measurement of urinary 2-hydroxyestradiol 17-sulfate, a potential placental antioxidant during pregnancy. Clin Chem 46: 373-378, 2000.

45. Ireson CR, Chander SK, Purohit A, Perera S, Newman SP, Parish D, Leese MP, Smith AC, Potter BV and Reed MJ: Pharmacokinetics and efficacy of 2-methoxyoestradiol and 2 -methoxyoestradiol-bis-sulphamate in vivo in rodents. $\mathrm{Br}$ J Cancer 90: 932-937, 2004. 